\title{
2-Chlorophenol Oxidation in Supercritical Water: Global Kinetics and Reaction Products
}

\author{
Ruokang Li, Phillip E. Savage, and David Szmukler \\ Dept. of Chemical Engineering, University of Michigan, Ann Arbor, MI 48109
}

\begin{abstract}
2-Chlorophenol (2CP) was oxidized in near-critical and supercritical water in a high-pressure plug-flow reactor. The global kinetics for 2CP disappearance were described by a rate law that was $0.88 \pm 0.06$ order in $2 C P, 0.41 \pm 0.12$ order in $\mathrm{O}_{2}$, and $0.34 \pm 0.17$ order in water. The activation energy was $11.0 \pm 3.8 \mathrm{kcal} / \mathrm{mol}$, and the Arrhenius pre-exponential factor was $10^{2.0 \pm 1.2} \mathrm{M}^{-0.63} \mathrm{~s}^{-1}$. The uncertainties represent $95 \%$ confidence intervals. The products of $2 \mathrm{CP}$ oxidation included $\mathrm{CO}$, $\mathrm{CO}_{2}, \mathrm{HCl}$, other chlorophenols, chlorohydroxybenzaldehydes, dichlorophenoxyphenols, dichlorobiphenols, and chlorinated dibenzodioxins and dibenzofuran. The molar yields of the organic products were determined for a set of experiments at $380^{\circ} \mathrm{C}$ and $278 \mathrm{~atm}$. The most abundant products were $2 \mathrm{CP}$ dimers such as dichlorophenoxyphenols and dichlorobiphenols, and the highest yield observed for any individual product was $0.6 \%$. Although the yields of these products were low, their selectivities were high. For example, at $3.6 \mathrm{~s}$, the shortest residence time studied under these conditions, about 50\% of the carbon in the 2CP that reacted appeared in $2 \mathrm{CP}$ dimers, $18 \%$ appeared as $\mathrm{CO}_{2}$, and the balance (32\%) was presumably in single-ring and ring-opening products. A reaction pathway analysis using the Delplot methodology revealed that the evolution of products from $2 C P$ oxidation in supercritical water was consistent with a reaction network comprising two parallel primary reactions. One primary reaction path led to dichlorophenoxyphenols and dichlorobiphenols whereas the second primary reaction led to single-ring and ringopening products. The $2 \mathrm{CP}$ dimers were converted to single-ring and ring-opening products, which were, in turn, ultimately oxidized to $\mathrm{CO}_{2}$.
\end{abstract}

\section{Introduction}

Supercritical water oxidation (SCWO) is a technology being advanced for the ultimate destruction of organic compounds. Organic carbon can be rapidly converted to $\mathrm{CO}_{2}$, hydrogen to $\mathrm{H}_{2} \mathrm{O}$, and chlorine to $\mathrm{HCl}$. Proposed reaction conditions include temperatures between 400 and $650^{\circ} \mathrm{C}$ and pressures around $250 \mathrm{~atm}$. These values are typically selected because water above its critical point $\left(T_{c}=374^{\circ} \mathrm{C}, P_{c}=218\right.$ atm) possesses a high solubility for both organics and oxygen. Thus, a single phase containing oxygen, organic, and water can exist at reaction conditions, and the rate of interphase mass transfer need not limit the reaction rate as it typically does at subcritical

Correspondence concerning this article should be addressed to P. E. Savage. conditions. Furthermore, the temperatures employed in SCW oxidation result in intrinsic reaction rates sufficiently high that the oxidation of organics goes essentially to completion on the order of a few minutes. Modell (1989) provides a more complete discussion of SCWO technology, and he delineates additional advantages of SCWO over more conventional waste treatment technologies.

One of the SCWO research frontiers that has been attracting attention in recent years is the reaction pathways, kinetics, and mechanisms. Tester and his colleagues (for example, Helling and Tester, 1987, 1988; Webley and Tester, 1989, 1991; Webley et al., 1991) have determined global reaction rate laws for the oxidation of several simple compounds such as $\mathrm{CO}, \mathrm{CH}_{4}$, and $\mathrm{NH}_{3}$ at a single pressure of 250 bar. These rate laws were then 
used to test the predictions of detailed chemical kinetics models. Yang and Eckert (1988) oxidized 4-chlorophenol in SCW and examined the effects of different homogeneous catalysts, the organic and oxygen concentrations, and temperature on the reaction rate. They detected $\mathrm{CO}_{2}$ and $\mathrm{CO}$ as the major gaseous products and 1,4-benzoquinone as the major liquid product. Wightman (1981) performed limited SCWO experiments with a large number of compounds and reported data that permitted a qualitative assessment of their relative reactivities. Finally, Savage and his colleagues (Thornton and Savage, 1990, 1992a,b; Li et al., 1992; Thornton et al., 1991) have recently provided the global kinetics, identified many of the reaction products, and investigated the reaction pathways for the oxidation of phenol in near-critical and supercritical water. Thornton and Savage (1992a) also provide a more thorough review of previous SCWO kinetics studies.

This article reports the results of an investigation into the global kinetics of and reaction products from 2-chlorophenol (2CP) oxidation in SCW . 2CP was selected as the reactant for this research because it is frequently found in industrial waste waters. It is generally considered to be resistant to biodegradation, and the literature provides only very limited data for the oxidation of 2CP in near-critical and supercritical water (Baillod et al., 1982; Dietrich et al., 1985; Levec, 1990; Staszak et al., 1987).

\section{Experimental}

The oxidation reactions were conducted in a plug-flow reactor. The reactor feed streams were prepared by dissolving high-pressure oxygen in deaerated, deionized, and distilled water at about $15^{\circ} \mathrm{C}$ in one feed tank, and loading an aqueous solution of $2 \mathrm{CP}$ into a second feed tank. This second vessel was blanketed with helium so that no oxygen would be present in the $2 \mathrm{CP}$ feed stream. The feed stream from each vessel was then brought to the desired operating pressure using individual Eldex model AA-100-S metering pumps, each with a nominal $0.1-10 \mathrm{~mL} / \mathrm{min}$ flow rate range and a maximum operating pressure of $340 \mathrm{~atm}$.

Each feed stream was then preheated by flowing through a 2 -m length of 0.0625 -in. (1.59-mm) OD $\times 0.010$-in. $(0.25-\mathrm{mm})$ thickness Hastelloy C-276 tubing coiled within a Techne model SBL-2 fluidized sand bath. This split feed arrangement ensured that no oxygen contacted $2 \mathrm{CP}$ before the reaction temperature and pressure had been achieved. The two feed streams were then mixed at the entrance to the reactor, which was fashioned from a length of 0.125 -in. (3.18-mm) OD $\times 0.035$-in. (0.89$\mathrm{mm}$ ) wall thickness Hastelloy C-276 tubing and coiled within the sand bath. The oxidation reactions were then conducted in this isothermal, isobaric, plug-flow reactor.

We performed $2 \mathrm{CP}$ pyrolysis experiments in the flow reactor, and the highest conversion achieved was less than $3 \%$, which occurred at $380^{\circ} \mathrm{C}$ and $278 \mathrm{~atm}$ and a residence time of about $120 \mathrm{~s}$. It was not possible to exclude all oxygen from the $2 \mathrm{CP}$ solution used in the pyrolysis experiments so a portion of this conversion is attributable to oxidation reactions. The residence times of the $2 \mathrm{CP}$ feed stream in the preheater line were always less than $120 \mathrm{~s}$ so the influence of pyrolytic reactions on the measured global kinetics is expected to be small.

The reactor effluent was cooled, depressurized, and then separated into liquid and vapor phases. The flow rates of each phase were measured, and these values were used along with the density of the reaction mixture at the reaction conditions to calculate the residence time in the reactor. The density of the reaction mixture was assumed to be the same as the density of water because the mixture was always over $99.8 \mathrm{~mol} \%$ water.

Products in the gas phase were analyzed using a dedicated Hewlett-Packard model 5890 Series II gas chromatograph equipped with a 1/8-in. OD Supelco Carboseive S-II permanent gas column and a thermal conductivity detector. The amount of $2 \mathrm{CP}$ that remained unreacted was determined by analyzing the liquid product samples using reverse-phase, high performance liquid chromatography. A mixture of $72 \mathrm{vol} \%$ deionized water and 28 vol $\%$ acetonitrile served as the mobile phase, and a Superco octadecyl-dimethylsilyl column served as the stationary phase. The variable wavelength uv-vis detector was set at $210 \mathrm{~nm}$. Quantitative results were obtained by comparing the integrated 2-chlorophenol peak areas with those of standard solutions. The concentration of chloride ion $\left(\mathrm{Cl}^{-}\right)$in the liquid product samples was measured using a Dionex ion chromatography system. A $0.025 \mathrm{M} \mathrm{Na}_{2} \mathrm{CO}_{3}$ and $0.025 \mathrm{M} \mathrm{NaHCO}_{3}$ aqueous solution served as the mobile phase. It flowed at 2 $\mathrm{ml} / \mathrm{min}$ through a Dionex AS4A column, and the chloride ion concentration was monitored using a conductivity detector.

The aqueous reactor effluent samples were also subjected to a liquid-liquid extraction protocol, which was similar to EPA Method 604 for phenols (Federal Register, 1984), in order to concentrate, identify, and quantify the reaction products. Ten $\mathrm{mL}$ of dichloromethane was used to extract the organic products from a $20 \mathrm{~mL}$ aqueous sample. The extraction was repeated three times so that $30 \mathrm{~mL}$ of dichloromethane was finally obtained. This dichloromethane solution was then placed in a Kuderna-Danish concentrator, which was immersed in a water bath. The bath temperature was gradually increased until only $1 \mathrm{~mL}$ of extract remained. A Hewlett-Packard model 5890 gas chromatograph with a model 5970 mass selective detector (GC/MS) was then used to identify these extracted reaction products. Quantification of the product concentrations was accomplished using a Hewlett-Packard 5890 gas chromatograph with a flame ionization detector. The sample constituents were separated on a $12 \mathrm{~m} \times 0.2 \mathrm{~mm}$ OD HP-1 capillary column using helium as the carrier gas. Detector response factors relative to the standard, 2,2' -biphenol, were determined experimentally for each product commercially available. The response factors for most of the compounds were around $\mathbf{1 . 0}$ except for a dichlorodibenzodioxin, which was 3.4 , and a dichlorobiphenol, which was 0.4 . The response factors for products that were not commercially available were assumed to be equal to those for an isomer of some other related compound. The uncertainty in these estimated response factors is about $\pm 20 \%$ for all of the products except dichlorophenoxyphenols, which had a much higher uncertainty. The reason for this higher uncertainty will be discussed in the section where quantitative data for the product yields are reported. Additional details about the reactor, experimental procedure, and analytical methods have been reported previously (Thornton, 1991; Thornton and Savage, 1990; Thornton et al., 1991).

\section{Global Kinetics of 2-Chlorophenol Disappearance}

Table 1 provides a complete listing of the results from 62 2CP oxidation experiments. These experiments were accom- 
Table 1. Summary of 2-Chlorophenol Oxidation Experiments

\begin{tabular}{|c|c|c|c|c|c|c|}
\hline $\begin{array}{l}T \\
{ }^{\circ} \mathrm{C} \\
\end{array}$ & $\begin{array}{r}P \\
\text { atm. }\end{array}$ & $\begin{array}{l}\tau \\
s \\
\end{array}$ & $\begin{array}{c}2 \mathrm{CP} \\
\text { Conc. } \\
\mathrm{M}\end{array}$ & $\begin{array}{c}\mathrm{O}_{2} \\
\text { Conc. } \\
\mathrm{M}\end{array}$ & $\begin{array}{c}\mathrm{H}_{2} \mathrm{O} \\
\text { Conc. } \\
\mathrm{M}\end{array}$ & $\begin{array}{l}X \\
\% \\
\end{array}$ \\
\hline 300 & 278 & 14.6 & $5.99 \times 10^{-4}$ & $4.12 \times 10^{-2}$ & 41.51 & 24.3 \\
\hline 330 & 278 & 13.6 & $5.51 \times 10^{-4}$ & $3.79 \times 10^{-2}$ & 38.20 & 29.5 \\
\hline 360 & 278 & 11.8 & $4.85 \times 10^{-4}$ & $3.33 \times 10^{-2}$ & 33.61 & 31.0 \\
\hline 380 & 185 & 13.2 & $8.03 \times 10^{-5}$ & $5.49 \times 10^{-3}$ & 5.71 & 8.6 \\
\hline 380 & 205 & 17.7 & $1.04 \times 10^{-4}$ & $7.12 \times 10^{-3}$ & 7.40 & 16.7 \\
\hline 380 & 219 & 19.0 & $1.32 \times 10^{-4}$ & $8.99 \times 10^{-3}$ & 9.28 & 23.6 \\
\hline 380 & 225 & 22.9 & $1.56 \times 10^{-4}$ & $1.06 \times 10^{-2}$ & 10.97 & 41.1 \\
\hline 380 & 225 & 26.8 & $1.54 \times 10^{-4}$ & $1.05 \times 10^{-2}$ & 10.97 & 60.6 \\
\hline 380 & 232 & 34.5 & $2.28 \times 10^{-4}$ & $1.55 \times 10^{-2}$ & 15.97 & 72.1 \\
\hline 380 & 246 & 24.1 & $3.42 \times 10^{-4}$ & $2.57 \times 10^{-2}$ & 24.22 & 65.2 \\
\hline 380 & 260 & 27.1 & $3.77 \times 10^{-4}$ & $2.89 \times 10^{-2}$ & 26.96 & 67.5 \\
\hline 380 & 278 & 20.4 & $3.19 \times 10^{-4}$ & $1.07 \times 10^{-2}$ & 28.42 & 45.7 \\
\hline 380 & 278 & 35.1 & $3.28 \times 10^{-4}$ & $9.63 \times 10^{-3}$ & 28.42 & 62.0 \\
\hline 380 & 278 & 49.2 & $3.70 \times 10^{-4}$ & $1.01 \times 10^{-2}$ & 28.42 & 76.0 \\
\hline 380 & 278 & 69.8 & $3.26 \times 10^{-4}$ & $9.76 \times 10^{-3}$ & 28.42 & 85.2 \\
\hline 380 & 278 & 5.9 & $3.86 \times 10^{-4}$ & $2.97 \times 10^{-2}$ & 28.42 & 17.2 \\
\hline 380 & 278 & 10.2 & $4.00 \times 10^{-4}$ & $2.87 \times 10^{-2}$ & 28.42 & 23.4 \\
\hline 380 & 278 & 21.1 & $4.02 \times 10^{-4}$ & $3.02 \times 10^{-2}$ & 28.42 & 59.0 \\
\hline 380 & 278 & 32.8 & $3.76 \times 10^{-4}$ & $3.22 \times 10^{-2}$ & 28.42 & 76.4 \\
\hline 380 & 278 & 44.4 & $3.84 \times 10^{-4}$ & $3.02 \times 10^{-2}$ & 28.42 & 88.9 \\
\hline 380 & 278 & 59.1 & $3.95 \times 10^{-4}$ & $3.08 \times 10^{-2}$ & 28.42 & 98.6 \\
\hline 380 & 278 & 19.9 & $9.90 \times 10^{-4}$ & $3.76 \times 10^{-2}$ & 28.42 & 57.5 \\
\hline 380 & 278 & 34.0 & $1.03 \times 10^{-3}$ & $3.50 \times 10^{-2}$ & 28.42 & 74.1 \\
\hline 380 & 278 & 47.3 & $1.04 \times 10^{-3}$ & $3.47 \times 10^{-2}$ & 28.42 & 93.2 \\
\hline 380 & 278 & 59.6 & $1.04 \times 10^{-3}$ & $3.65 \times 10^{-2}$ & 28.42 & 98.5 \\
\hline 380 & 278 & 7.2 & $1.41 \times 10^{-3}$ & $3.60 \times 10^{-2}$ & 28.42 & 19.1 \\
\hline 380 & 278 & 29.6 & $1.55 \times 10^{-3}$ & $3.64 \times 10^{-2}$ & 28.42 & 68.9 \\
\hline 380 & 278 & 40.2 & $1.60 \times 10^{-3}$ & $3.58 \times 10^{-2}$ & 28.42 & 82.4 \\
\hline 380 & 278 & 50.1 & $1.48 \times 10^{-3}$ & $3.74 \times 10^{-2}$ & 28.42 & 93.6 \\
\hline 380 & 278 & 58.6 & $1.57 \times 10^{-3}$ & $3.61 \times 10^{-2}$ & 28.42 & 99.0 \\
\hline 380 & 278 & 69.5 & $1.64 \times 10^{-3}$ & $3.53 \times 10^{-2}$ & 28.42 & 98.6 \\
\hline 380 & 278 & 3.6 & $1.95 \times 10^{-3}$ & $4.09 \times 10^{-2}$ & 28.42 & 9.2 \\
\hline 380 & 278 & 5.2 & $1.98 \times 10^{-3}$ & $4.29 \times 10^{-2}$ & 28.42 & 11.4 \\
\hline 380 & 278 & 7.3 & $2.05 \times 10^{-3}$ & $4.19 \times 10^{-2}$ & 28.42 & 13.2 \\
\hline 380 & 278 & 10.1 & $2.03 \times 10^{-3}$ & $3.97 \times 10^{-2}$ & 28.42 & 18.9 \\
\hline 380 & 278 & 13.9 & $2.04 \times 10^{-3}$ & $4.20 \times 10^{-2}$ & 28.42 & 34.7 \\
\hline 380 & 278 & 18.6 & $2.13 \times 10^{-3}$ & $3.80 \times 10^{-2}$ & 28.42 & 46.7 \\
\hline 380 & 278 & 24.7 & $2.07 \times 10^{-3}$ & $3.88 \times 10^{-2}$ & 28.42 & 54.7 \\
\hline 380 & 278 & 29.5 & $2.04 \times 10^{-3}$ & $4.07 \times 10^{-2}$ & 28.42 & 67.2 \\
\hline 380 & 278 & 33.9 & $2.15 \times 10^{-3}$ & $3.77 \times 10^{-2}$ & 28.42 & 69.1 \\
\hline 380 & 278 & 40.0 & $2.09 \times 10^{-3}$ & $3.99 \times 10^{-2}$ & 28.42 & 78.7 \\
\hline 380 & 278 & 49.5 & $1.97 \times 10^{-3}$ & $4.14 \times 10^{-2}$ & 28.42 & 82.1 \\
\hline 380 & 278 & 57.4 & $2.12 \times 10^{-3}$ & $3.95 \times 10^{-2}$ & 28.42 & 97.1 \\
\hline 380 & 278 & 67.5 & $2.05 \times 10^{-3}$ & $4.03 \times 10^{-2}$ & 28.42 & 99.7 \\
\hline 380 & 278 & 29.4 & $1.82 \times 10^{-3}$ & $1.94 \times 10^{-2}$ & 28.42 & 75.4 \\
\hline 380 & 278 & 39.7 & $1.98 \times 10^{-4}$ & $1.47 \times 10^{-2}$ & 28.42 & 79.5 \\
\hline 380 & 278 & 41.0 & $2.32 \times 10^{-4}$ & $1.21 \times 10^{-2}$ & 28.42 & 70.9 \\
\hline 380 & 278 & 27.9 & $2.52 \times 10^{-4}$ & $1.42 \times 10^{-2}$ & 28.42 & 61.0 \\
\hline 380 & 278 & 40.5 & $3.02 \times 10^{-4}$ & $7.01 \times 10^{-3}$ & 28.42 & 58.3 \\
\hline 380 & 278 & 38.4 & $4.41 \times 10^{-4}$ & $4.44 \times 10^{-2}$ & 28.42 & 92.2 \\
\hline 380 & 278 & 40.9 & $5.79 \times 10^{-4}$ & $3.63 \times 10^{-2}$ & 28.42 & 83.5 \\
\hline 380 & 278 & 11.4 & $6.27 \times 10^{-4}$ & $3.47 \times 10^{-2}$ & 28.42 & 28.4 \\
\hline 380 & 278 & 5.8 & $6.46 \times 10^{-4}$ & $3.41 \times 10^{-2}$ & 28.42 & 20.7 \\
\hline 380 & 278 & 40.5 & $8.17 \times 10^{-4}$ & $2.21 \times 10^{-2}$ & 28.42 & 66.4 \\
\hline 380 & 278 & 14.7 & $1.13 \times 10^{-3}$ & $3.73 \times 10^{-2}$ & 28.42 & 30.4 \\
\hline 380 & 294 & 29.9 & $4.06 \times 10^{-4}$ & $3.19 \times 10^{-2}$ & 29.37 & 76.0 \\
\hline 390 & 278 & 45.2 & $3.15 \times 10^{-4}$ & $2.58 \times 10^{-2}$ & 23.09 & 89.1 \\
\hline 400 & 278 & 28.1 & $1.98 \times 10^{-4}$ & $1.62 \times 10^{-2}$ & 14.50 & 69.7 \\
\hline 410 & 278 & 21.6 & $1.50 \times 10^{-4}$ & $1.22 \times 10^{-2}$ & 10.96 & 54.4 \\
\hline 420 & 278 & 10.0 & $5.04 \times 10^{-4}$ & $1.27 \times 10^{-2}$ & 9.40 & 25.4 \\
\hline 420 & 278 & 16.9 & $5.08 \times 10^{-4}$ & $1.26 \times 10^{-2}$ & 9.40 & 40.7 \\
\hline 420 & 278 & 24.0 & $5.43 \times 10^{-4}$ & $1.22 \times 10^{-2}$ & 9.40 & 58.1 \\
\hline
\end{tabular}

plished at temperatures between 300 and $420^{\circ} \mathrm{C}$ and pressures from 185 to $294 \mathrm{~atm}$. These conditions included oxidation in both near-critical and supercritical water. Reactor residence times ranged from 3.6 to $69.8 \mathrm{~s}$. The initial $2 \mathrm{CP}$ concentrations were between $8.0 \times 10^{-5}$ and $2.2 \times 10^{-3} \mathrm{M}$, and $2 \mathrm{CP}$ was always the limiting reactant. The excess oxygen was between $192 \%$ and $1,680 \%$, which resulted in oxygen concentrations between $5.49 \times 10^{-3}$ and $4.44 \times 10^{-2} \mathrm{M}$. The final column in Table 1 provides the $2 \mathrm{CP}$ conversion, $X$, which was calculated as $X=1-[2 \mathrm{CP}] /[2 \mathrm{CP}]_{o}$, where $[2 \mathrm{CP}]_{o}$ is the $2 \mathrm{CP}$ concentration at the reactor entrance.

The objectives of our global kinetics analysis were to determine the Arrhenius parameters $\left(A\right.$ and $\left.E_{a}\right)$ and the reaction orders $(a, b$, and $c)$ for $2 \mathrm{CP}, \mathrm{O}_{2}$, and $\mathrm{H}_{2} \mathrm{O}$ for the rate expression for $2 \mathrm{CP}$ disappearance during $\mathrm{SCW}$ oxidation given in Eq. 1. Similar power-law expressions have been used frequently to correlate SCW oxidation kinetics, so our use of the same type of expression here will provide a basis for comparison with previous work. These rate laws typically capture the general trends in the data, but they cannot be expected to capture the details of the complex oxidation chemistry.

$$
\text { Rate }=A \exp \left(-\frac{E_{a}}{R T}\right)[2 C P]^{a}\left[\mathrm{O}_{2}\right]^{b}\left[\mathrm{H}_{2} \mathrm{O}\right]^{c}
$$

The rate constant was taken to be independent of pressure (that is, $\Delta V^{\ddagger}=0$ ). Thus, all pressure effects were manifested in the variation of the reactant concentrations since $\mathrm{SCW}$ is a compressible fluid.

Combining the rate law of Eq. 1 with the definition of conversion and the design equation (Fogler, 1992) for a constant-volume, plug-flow reactor leads to

$$
\frac{d X}{d \tau}=A \exp \left(-\frac{E_{a}}{R T}\right)[2 C P]_{o}^{a-1}(1-X)^{a}\left[\mathrm{O}_{2}\right]^{b}\left[\mathrm{H}_{2} \mathrm{O}\right]^{c}
$$

The reactor operated isobarically and isothermally, and oxygen and water were always present in large excess. Therefore, the concentrations of $\mathrm{O}_{2}$ and $\mathrm{H}_{2} \mathrm{O}$ can be taken to be conversion invariant and approximately equal to their initial concentrations. Equation 2 can then be separated and integrated analytically. Using the initial condition of $X=0$ at $\tau=0$ yields

$$
\begin{gathered}
{\left[(1-X)^{1-a}-1\right]=(a-1) A \exp \left(-\frac{E_{a}}{R T}\right)[2 C P]_{o}^{a-1}\left[\mathrm{O}_{2}\right]_{o}^{b}\left[\mathrm{H}_{2} \mathrm{O}\right]_{o}^{c} \tau} \\
\text { if } a \neq 1 \\
\ln (1-X)=-A \exp \left(-\frac{E_{a}}{R T}\right)\left[\mathrm{O}_{2}\right]_{o}^{b}\left[\mathrm{H}_{2} \mathrm{O}\right]_{o}^{c} \tau \quad \text { if } a=1
\end{gathered}
$$

Optimized values for the parameters $a, b, c, A$, and $E_{a}$ in Eq. 3 were obtained by applying a nonlinear regression method to the data in Table I. The objective function minimized in the regression method was the sum of the squares of the differences between the values of $X$ calculated from Eq. 3 and those measured experimentally. The optimal values of the kinetics parameters lead to the global rate law of Eq. 5 to describe $2 \mathrm{CP}$ oxidation. 


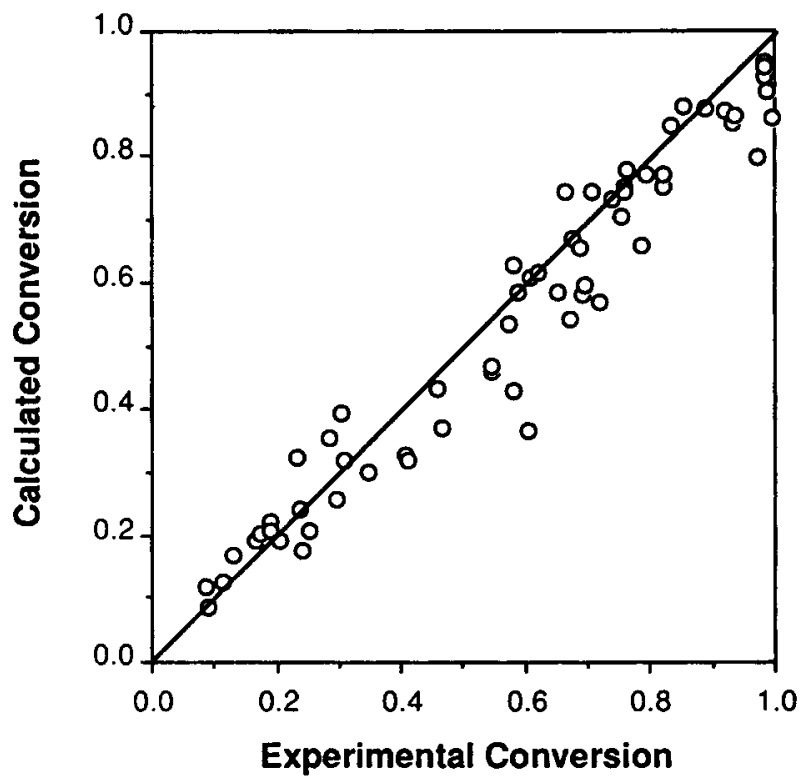

Figure 1. Comparison of experimental and calculated 2 chlorophenol conversions.

Calculated conversions are based on rate law of Eq. 5 .

$$
\begin{aligned}
\text { Rate }=10^{2.0 \pm 1.2} \exp & \left(-\frac{11,000 \pm 3,800}{R T}\right) \\
& \times[2 C P]^{0.88 \pm 0.06}\left[\mathrm{O}_{2}\right]^{0.41 \pm 0.12}\left[\mathrm{H}_{2} \mathrm{O}\right]^{0.34 \pm 0.17}
\end{aligned}
$$

The rate is in $\mathrm{mol} / \mathrm{L} \cdot \mathrm{s}$, all concentrations are in $\mathrm{mol} / \mathrm{L}$, and the activation energy is in $\mathrm{cal} / \mathrm{mol}$. The uncertainties expressed in Eq. 5 are the $95 \%$ confidence intervals.

Figure 1 shows the parity plot of the experimental $2 \mathrm{CP}$ conversions and those calculated from Eq. 3 with the optimized rate law parameters. This plot verifies that the estimated parameters provide a good description of the experimental data.

Examining the parameter values in Eq. 5, one observes that the reaction order with respect to $\mathrm{O}_{2}$ is greater than zero. That oxygen has an effect on the global kinetics of SCW oxidation is consistent with recent work with phenol (Thornton and Savage, 1992a) and methane (Webley and Tester, 1991). Most earlier SCWO research (for example, Helling and Tester, 1987; Yang and Eckert, 1988) had found that the reaction rate did not depend on the $\mathrm{O}_{2}$ concentration. The rate law in Eq. 5 also shows that increasing the pressure at constant temperature and constant $2 \mathrm{CP}$ and $\mathrm{O}_{2}$ concentrations increases the reaction rate. This acceleration is accounted for by including the water concentration in the rate law. Higher pressures result in higher water densities. Finally, temperature has two competing effects on the reaction rate. Increasing the temperature at constant pressure increases the rate constant, but it decreases the reaction density and, hence, the concentrations. The relative importance of these competing effects has been explored in more detail in a previous report on phenol oxidation in SCW (Thornton and Savage, 1992a).

Comparing the reaction orders and activation energy for $2 \mathrm{CP}$ given in Eq. 5 with those reported previously for phenol oxidation in SCW (Thornton and Savage, 1992a) reveals that the reaction order for water differed the most for these two compounds. It was $0.34 \pm 0.17$ for $2 \mathrm{CP}$ but 0.7 for phenol. The reaction orders for the organic compound were $0.88 \pm 0.06$ and 1.0 for $2 \mathrm{CP}$ and phenol, respectively, and those for oxygen were $0.41 \pm 0.12$ and 0.5 , respectively. The activation energies were $11.0 \Omega 3.8 \mathrm{kcal} / \mathrm{mol}$ and $12.4 \mathrm{kcal} / \mathrm{mol}$, respectively. The Arrhenius pre-exponential factors for both $2 \mathrm{CP}$ and phenol were on the order of $10^{2}$, a value that is much lower than the pre-exponential factors for most elementary reactions. This result indicates that the oxidation mechanism is complex and undoubtedly comprises a large number of elementary steps.

Further comparison of the present rate law with previous kinetics studies can be made by considering rate data reported by Yang (1988) and Yang and Eckert (1988) for the uncatalyzed oxidation of 4-chlorophenol. These investigators provide average rates for 4-chlorophenol oxidation at $400^{\circ} \mathrm{C}$ and $240 \mathrm{~atm}$ and at $340^{\circ} \mathrm{C}$ and $140 \mathrm{~atm}$. The first set of conditions is within the temperature and pressure range used in the present investigation whereas the second set is not. Further, Yang and Eckert (1988) frequently used much higher organic and oxygen concentrations than those used in the present work. Thus, a comparison of the present rate law for 2-chlorophenol oxidation with the data of Yang and Eckert (1988) for 4-chlorophenol requires some extrapolation.

Figure 2 summarizes this comparison. Figure $2 \mathrm{a}$ provides the average 4-chlorophenol oxidation rates reported by Yang (1988) for the two different reaction conditions as a function of the 4-chlorophenol concentration. The oxygen concentration was ten times the stoichiometric amount. The discrete points are experimental data (Yang and Eckert, 1988), and the solid curves in Figure $2 \mathrm{a}$ are the predicted rates based on the rate law of Eq. 5. Inspection of Figure $2 \mathrm{a}$ reveals that the rate law reported here for 2-chlorophenol quantitatively predicts the rates of 4-chlorophenol oxidation at $400^{\circ} \mathrm{C}$ and $240 \mathrm{~atm}$ reported by Yang and Eckert (1988). This quantitative agreement is probably fortuitous given that the rate law is being extrapolated to concentrations nearly an order of magnitude higher than those used to determine its parameters and that the data and the rate law are for two different chlorophenol isomers. Further inspection of this figure shows that the rate law consistently underpredicted the rate of 4-chlorophenol oxidation at $340^{\circ} \mathrm{C}$ and $140 \mathrm{~atm}$. Nevertheless, the trend in the data for 4-chlorophenol oxidation at these milder conditions is predicted by the present global rate law for 2-chlorophenol.

Figure $2 b$ provides Yang's (1988) data for the oxidation of stoichiometric mixtures of 4-chlorophenol and oxygen. The solid lines are the rates calculated from Eq. 5. Once again, we observe good agreement between the data and rate law predictions at $400^{\circ} \mathrm{C}$ and $240 \mathrm{~atm}$, but a consistent underprediction of the rates at $340^{\circ} \mathrm{C}$ and $140 \mathrm{~atm}$. The rate law does capture the linear trend in the data at these milder conditions, however, and it possesses approximately the same slope as the data.

Yang and Eckert (1988) interpreted the data in Figure 2 as indicating that the global rate law was zero-order in oxygen, first-order in chlorophenol at low concentrations, and secondorder in chlorophenol at high concentrations. We show here that the trends in these data are consistent with the form of the rate law in Eq. 5, which has a nonzero reaction order for oxygen, a constant reaction order for chlorophenol, and the sum of the chlorophenol and oxygen orders exceeding unity.

To summarize this comparison, it appears that the rate law in Eq. 5, which was developed for 2-chlorophenol oxidation, 


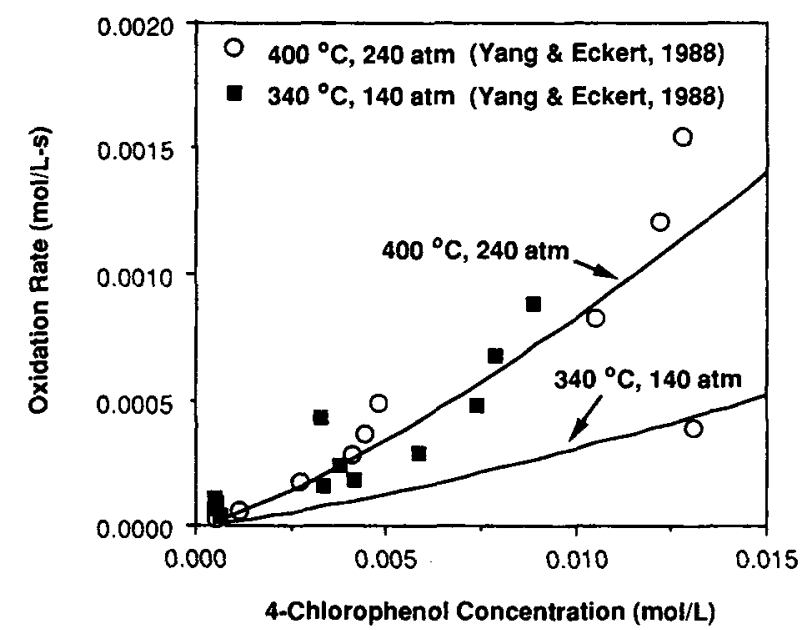

(a)

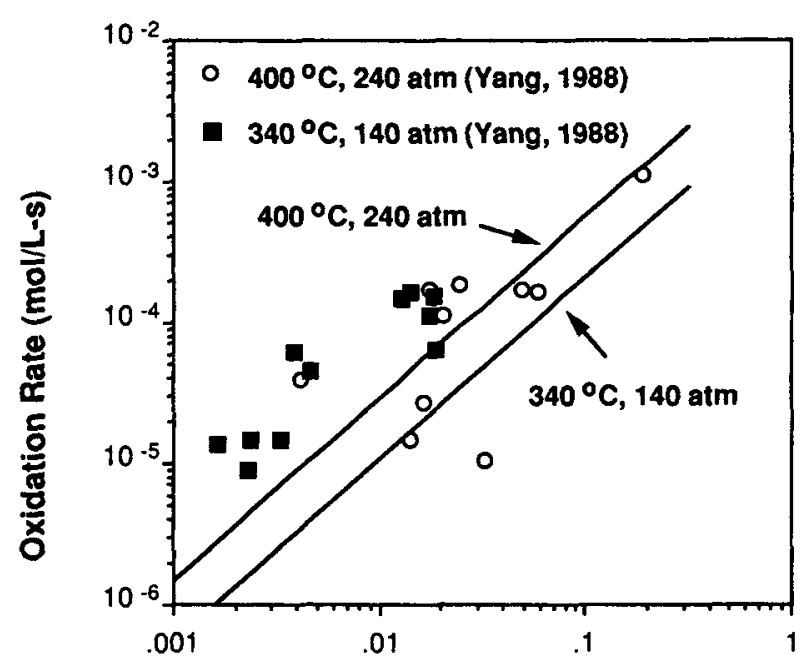

Oxygen Concentration (mol/L)

(b)

Figure 2. Comparison of rate data for 4-chlorophenol oxidation (Yang, 1988) and predictions based on 2-chlorophenol rate law in Eq. 5.

a. $900 \%$ excess oxygen; b. Stoichiometric oxygen.

can be extrapolated to predict the trends in, and at times quantitative values of, the rates of 4-chlorophenol disappearance reported by Yang (1988). This observation suggests that the key features of the SCW oxidation chemistry for these two chlorophenol isomers may be similar.

\section{Reaction Products}

One of the focal points of our work with $2 \mathrm{CP}$ has been the identification and quantification of the yields of the products from incomplete oxidation in SCW. Earlier research into phenol oxidation in SCW showed that dimers such as phenoxyphenols and biphenol were major primary products (Thornton et al., 1991; Thornton and Savage, 1992b). Thus, we were particularly interested in determining whether analogous products arose from $2 \mathrm{CP}$ oxidation in $\mathrm{SCW}$. In this section of the article, we first present the identities of different $2 \mathrm{CP}$ oxidation products, and then we present quantitative information about the products' molar yields and selectivities. These quantitative data were obtained from a set of experiments accomplished at nominal reaction conditions of $380^{\circ} \mathrm{C}, 278 \mathrm{~atm},[2 \mathrm{CP}]_{o}=0.0020$ $M$, and $180 \%$ excess oxygen.

\section{Product identities}

$\mathrm{CO}_{2}$ and $\mathrm{CO}$ were the only gas-phase products consistently detected in appreciable yields. Ion chromatography revealed the presence of chloride ion (presumably from dissociation of $\mathrm{HCl})$ in the aqueous phase of the reactor effluent. GC/MS analysis of the aqueous-phase products extracted in dichloromethane revealed a very large number of reaction products. Figure 3 displays a representative total ion chromatogram, which corresponds to an oxidation experiment at $380^{\circ} \mathrm{C}, 278$ atm, and $24.7 \mathrm{~s}$ using a feed stream containing $0.0020 \mathrm{M} 2 \mathrm{CP}$ and $0.0388 \mathrm{M}(\approx 180 \%$ excess) oxygen at reaction conditions. The identities of many of the compounds are given in Figure 3 , and an assessment of the reliability of these identifications is summarized in Table 2. Methods of product identification included inspection of the mass spectra, searching the GC-MS computer library for compounds with similar mass spectra, comparing the mass spectra of products with mass spectra of authentic compounds acquired on the same GC-MS, and comparing the GC retention times of products and authentic compounds.

Peak 2 in Figure 3 is the reactant, $2 \mathrm{CP}$, and peak 12 is the standard, 2,2' -biphenol, which was used to quantify the reaction products. Background experiments revealed that $2,2^{\prime}$ biphenol was not one of the reaction products. Nine of the reaction products (peaks 1, 3-6, 9, 13, and 22 in Figure 3) were positively identified. The chromatographic analysis did not completely resolve 3- and 4-chlorophenol so they appeared as the single peak numbered 6 in Figure 3. The positive identifications given in Figure 3 and Table 2 were obtained by matching both the mass spectrum and GC retention time for each compound with those of the authentic compound. This method could not be used to positively identify all of the remaining products because authentic standards were not commercially available. In these cases we relied on an inspection of the products' mass spectra and a comparison of these spectra with spectra stored in the computer workstation library. For example, consider the compounds corresponding to peaks 7,8 , and 11 , which we identified as chlorohydroxybenzaldehyde isomers. The mass spectra for these products had a molecular ion peak at $m / z=156$, which provided the molecular weight. Additionally, the intensity of the peak at $m / z=158$ was about $1 / 3$ of the intensity of the molecular ion peak, which indicated that the molecule contained a single chlorine atom because the ratio of the natural abundance of ${ }^{37} \mathrm{Cl}$ to ${ }^{35} \mathrm{Cl}$ is 0.325 (Silverstein et al., 1991). Thus, the molecular formula for these products was $\mathrm{C}_{7} \mathrm{H}_{5} \mathrm{O}_{2} \mathrm{Cl}$. A large number of organic compounds have this molecular formula, but a much smaller number will also be consistent with the fragmentation pattern apparent in the mass spectra. The fragmentation patterns for these products all showed a peak at $m / z=155$ that had an abundance greater than the molecular ion peak. The presence of an M-1 peak that is larger than the molecular ion peak can be indicative of an aromatic aldehyde, and it arises from loss of the aldehydic hydrogen. The M-1 ion can then eliminate $\mathrm{CO}$ to give a peak 


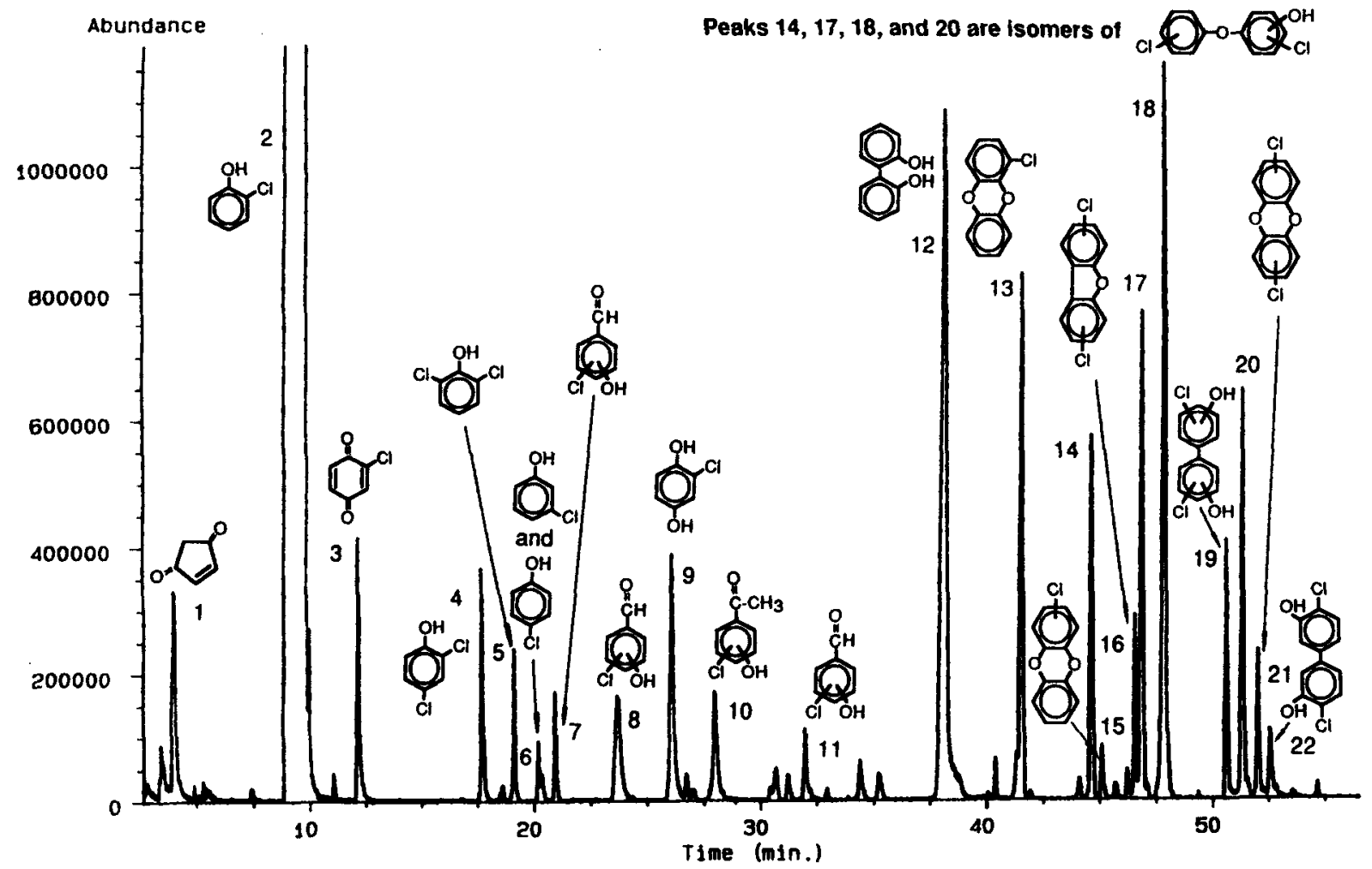

Figure 3. Total ion chromatogram of 2-chlorophenol oxidation products (nominal reaction conditions were $380^{\circ} \mathrm{C}$, $278 \mathrm{~atm}, 0.0020 \mathrm{M} 2 \mathrm{CP}, 180 \%$ excess oxygen, and $24.7 \mathrm{~s}$ residence time).

at 127, which was also present in the mass spectrum of each of these products. Thus, synthesizing all of the available information from the mass spectrum led to the identification of these three peaks as chlorohydroxybenzaldehyde isomers. Corroboration of this product identification was obtained by ob- serving a very good match between the mass spectra of these products and that of 5-chloro-2-hydroxybenzaldehyde, which was available in the computer library. Products such as the chlorohydroxybenzaldehydes, whose identities depended upon inspection of their mass fragmentation patterns and a match

Table 2. Summary of Produet Identification

\begin{tabular}{|c|c|c|}
\hline $\begin{array}{c}\text { Peak No. } \\
\text { in Fig. } 3\end{array}$ & Identity & Comments \\
\hline $\begin{array}{l}1 \\
2 \\
3 \\
4 \\
5\end{array}$ & $\begin{array}{l}\text { cyclopent-2-en-1,4-dione } \\
\text { 2-chlorophenol } \\
\text { 2-chloro-1,4-benzoquinone } \\
\text { 2,4-dichlorophenol } \\
\text { 2,6-dichlorophenol } \\
4 \text { (\& 3)-chlorophenol }\end{array}$ & $\begin{array}{l}\text { Positive identification } \\
\text { Reactant } \\
\text { Positive identification } \\
\text { Positive identification } \\
\text { Positive identification } \\
\text { Positive identification }\end{array}$ \\
\hline $\begin{array}{r}7 \\
8 \\
9 \\
10 \\
11 \\
12\end{array}$ & $\begin{array}{l}\text { chlorohydroxybenzaldehyde } \\
\text { chlorohydroxybenzaldehyde } \\
\text { chloro-hydroquinone } \\
\text { (chlorohydroxyphenyl)-ethanone } \\
\text { chlorohydroxybenzaldehyde } \\
2,2^{\prime} \text {-biphenol }\end{array}$ & $\begin{array}{l}\mathrm{MW}=156,1 \mathrm{Cl} \text { atom, library match } \\
\mathrm{MW}=156,1 \mathrm{Cl} \text { atom, library match } \\
\text { Positive identification } \\
\mathrm{MW}=170,1 \mathrm{Cl} \text { atom, library match } \\
\mathrm{MW}=156,1 \mathrm{Cl} \text { atom, library match } \\
\text { Standard }\end{array}$ \\
\hline $\begin{array}{l}13 \\
14 \\
15 \\
16 \\
17\end{array}$ & $\begin{array}{l}\text { 1-chlorodibenzodioxin } \\
\text { dichlorophenoxyphenol } \\
\text { chlorodibenzodioxin } \\
\text { dichlorodibenzofuran } \\
\text { dichlorophenoxyphenol }\end{array}$ & $\begin{array}{l}\text { Positive identification } \\
\mathrm{MW}=254,2 \mathrm{Cl} \text { atoms } \\
\mathrm{MW}=218,1 \mathrm{Cl} \text { atom, library match } \\
\mathrm{MW}=236,2 \mathrm{Cl} \text { atoms, library match } \\
\mathrm{MW}=254,2 \mathrm{Cl} \text { atoms }\end{array}$ \\
\hline $\begin{array}{l}18 \\
19 \\
20 \\
21 \\
22\end{array}$ & $\begin{array}{l}\text { dichlorophenoxyphenol } \\
\text { dichlorobiphenol } \\
\text { dichlorophenoxyphenol } \\
\text { dichlorodibenzodioxin } \\
4,4^{\prime} \text {-dichloro-3,3'-biphenol }\end{array}$ & $\begin{array}{l}\mathrm{MW}=254,2 \mathrm{Cl} \text { atoms } \\
\mathrm{MW}=254,2 \mathrm{Cl} \text { atoms } \\
\mathrm{MW}=254,2 \mathrm{Cl} \text { atoms } \\
\mathrm{MW}=252,2 \mathrm{Cl} \text { atoms, library match } \\
\text { Positive identification }\end{array}$ \\
\hline
\end{tabular}

"Both retention time and mass spectrum of product match those of authentic compound. 
with library mass spectra, are so denoted in Table 2 . We believe these identifications are correct, but they remain tentative because we could not verify the retention times and mass spectra with authentic compounds. Using the approach illustrated above, we also identified peaks 15,16 , and 21 as a chlorodibenzodioxin, a dichlorodibenzofuran, and a dichlorodibenzodioxin, respectively, because of the good match between the products' mass spectra and those of reference spectra stored in the computer library. Finally, there existed a group of peaks for which the computer library provided no good matches with reference spectra. These compounds (peak numbers 14, 17, 18 , and 20) showed a strong molecular ion peak at $\mathrm{m} / z=254$ and contained 2 chlorine atoms. They also exhibited strong peaks at $m / z=219$ and 184 , which resulted from the loss of 1 and $2 \mathrm{Cl}$ atoms, respectively. Thus, the molecular formula of these compounds is $\mathrm{C}_{12} \mathrm{H}_{8} \mathrm{O}_{2} \mathrm{Cl}_{2}$. Probable reaction products consistent with this formula include dichlorophenoxyphenols and dichlorobiphenols. [The nonchlorinated analogs of these compounds were major products from phenol oxidation in SCW (Thornton et al., 1991).] The mass fragmentation patterns for peaks $14,17,18$, and 20 did not resemble the computer library spectrum for a dichlorobiphenol. Thus, we concluded that peaks $14,17,18$, and 20 were due to dichlorophenoxyphenol isomers.

The discussion above shows that the reaction products extracted from the aqueous reactor effluent into dichloromethane can be roughly categorized into five groups: chlorinated and nonchlorinated cyclodiones (peaks 1 and 3), chlorinated phenols (peaks 4, 5, 6, and 9), chlorinated hydroxybenzaldehydes and hydroxyphenylethanone (peaks $7,8,10$, and 11), chlorinated dibenzodioxins and dibenzofuran (peaks 13,15, 16, and 21 ), and chlorinated phenoxyphenols and biphenols (peaks 14, 17-20, and 22). In Yang's report on 4-chlorophenol oxidation in SCW, only benzoquinone, which belongs to the first group was found in the uncatalyzed reactions (Yang, 1988). Metalcatalyzed homogeneous reactions, however, led to products that would fall within both the first and second groups. Yang reported no products from the third, fourth or fifth groups.

\section{Product yields}

Having identified a large number of the $2 \mathrm{CP}$ oxidation products, we next quantified these products' molar yields. Here we define molar yield as the molar concentration of the product in the reactor effluent divided by the molar concentration of $2 \mathrm{CP}$ at the reactor entrance. Table 3 provides the molar yields of the 20 identified organic reaction products at 13 different residence times for SCWO of $2 \mathrm{CP}$ at nominal reaction conditions of $380^{\circ} \mathrm{C}, 278 \mathrm{~atm},[2 \mathrm{CP}]_{o}=0.0020 \mathrm{M}$, and $180 \%$ excess oxygen. We note here that the uncertainty in most of the yields is $\pm 20 \%$, but the uncertainty in the dichlorophenoxyphenol yields is much larger because the lack of authentic standards prevented us from determining detector response factors experimentally. The mean response factor for related compounds (for example, a set of dichlorophenols and $2 \mathrm{CP}$ dimers) was 1.5 , but the range of response factors was from 0.4 for a dichlorodibenzodioxin to 3.4 for a dichlorobiphenol. This large variation in detector response was obtained from thermal conductivity, flame ionization, and mass spectrometric detectors. We used the mean response factor of 1.5 to calculate the dichlorophenoxyphenol yields reported in Table 3.
The yields of each of the individual products were always low. No product ever possessed a yield of greater than 0.01 $(1 \%)$. The most abundant products at short reaction times (less than $10 \mathrm{sec}$ ) were the dichlorophenoxyphenols (peaks 14,17 , 18 , and 20) and dichlorobiphenols (peaks 19 and 22). The yields of these products decreased with increasing residence time, however, and they were less than $0.1 \%$ after about $55 \mathrm{~s}$. At intermediate reaction times $(20-30 \mathrm{sec})$ the cyclodiones (peaks 1 and 3), 2-chlorohydroquinone (peak 9), and 1-chlorodibenzodioxin (peak 13) were among the most abundant products. The temporal variation of the molar yields for each of these products reveals a maximum between 30 and $50 \mathrm{~s}$, which suggests that these products underwent further oxidative degradation. Finally, at $67.5 \mathrm{~s}$, the longest residence time studied at these conditions, the only products present in concentrations above the detection limits included the cyclodiones, the dichlorophenoxyphenols, 1-chlorodibenzodioxin (peak 13) and a dichlorodibenzofuran (peak 16). The persistence of these latter two compounds is consistent with previous work with phenol oxidation in SCW (Thornton et al., 1991; Thornton and Savage, 1992b), which showed that dibenzofuran and dibenzodioxin were among the last of the phenol dimers to be degraded.

Figure 4 displays the carbon yield (moles of carbon atoms in product/moles of carbon atoms fed to reactor) for the identified organic products, $\mathrm{CO}$ plus $\mathrm{CO}_{2}$, and $2 \mathrm{CP}$ as a function of residence time. At short residence times, where the $2 \mathrm{CP}$ conversion was low, the carbon yield in the extracted organic products was about three times as high as the yield in the carbon oxides. As the residence time increased, however, the carbon oxide yield increased steadily whereas the carbon yield in the extracted products decreased. At $67.5 \mathrm{~s}$ the $\mathrm{CO}+\mathrm{CO}_{2}$ yield was $58.1 \%$ while the carbon yield in the extracted organic products was $0.5 \%$. The total amount of carbon contained in the identified products (both gas and liquid) is also plotted in Figure 4. The total carbon recovery decreased from about $98 \%$ at $3.6 \mathrm{~s}$ where the $2 \mathrm{CP}$ conversion was $9.2 \%$ to about $60 \%$ at $67.5 \mathrm{~s}$, where the conversion of $2 \mathrm{CP}$ was $99.7 \%$. Presumably, the balance of the carbon resides in ring-opening products such as low-molecular-weight carboxylic acids. Our GC-MS analyses and extraction protocol did not include identification or quantification of such products, but previous work revealed that such products are formed from phenol oxidation in SCW (Thornton and Savage, 1990).

Figure 5, which displays the temporal variation of the $\mathrm{Cl}$ yield for 2CP oxidation, reveals that very little of the chlorine in the reaction products was associated with organic compounds. Most of it appeared as $\mathrm{Cl}^{-}$in the cooled and depressurized reactor effluent. The $\mathrm{Cl}^{-}$presumably arose from the dissociation of $\mathrm{HCl}$. The total $\mathrm{Cl}$ yield was always around $100 \%$ indicating essentially complete recovery of $\mathrm{Cl}$. At times, however, experimental uncertainty in the ion chromatography led to total $\mathrm{Cl}$ yields exceeding $100 \%$.

\section{Implications to SCW oxidation pathways}

The data in Table 3 showed that the products identified as dichlorophenoxyphenol and dichlorobiphenol isomers were the most abundant reaction products at short residence times and that their yields decreased with increasing residence time. These observations suggest that these products form directly from 
Table 3. Molar Yield of Oxidation Products

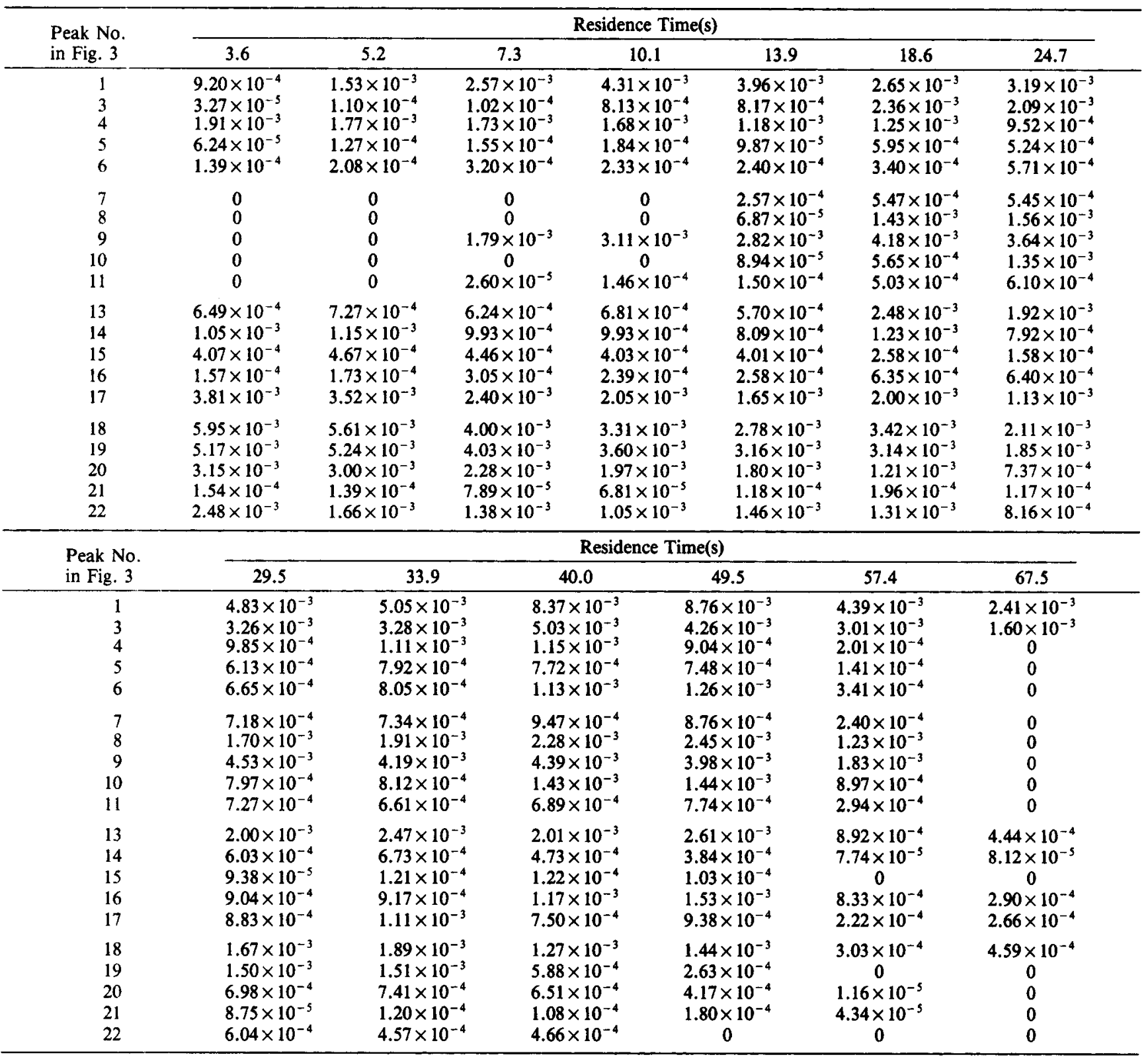

$2 \mathrm{CP}$ and then undergo reactions to form other products. Verification of this postulated scenario can be obtained by using the Delplot method for reaction pathway resolution (Bhore et al., 1990). This method, in its simplest form, requires plots of selectivity (moles product formed/moles reactant reacted) as a function of conversion. These plots are termed first rank Delplots. Primary products, those that form directly from the reactant, possess positive $y$-intercepts on a first rank Delplot. Products that appear later in the reaction network possess $y$ intercepts equal to zero. Figure 6 displays a first rank Delplot for the four dichlorophenoxyphenol isomers. It is clear that extrapolation of the data in Figure 6 to zero conversion leads to a positive $y$-intercept for each of the products. Thus, each of these products forms directly from $2 \mathrm{CP}$. The decrease in selectivity with conversion is consistent with these products participating in secondary reactions. The Delplots for the dichlorobiphenols were similar.
Applying the Delplot methodology to the other 14 reaction products in Table 3 revealed only one additional compound that was a major primary product. This compound was 2,4dichlorophenol. Here we define a major product as one that possessed a selectivity greater than 0.02 at at least one residence time. Thus, the major primary products from $2 \mathrm{CP}$ oxidation in SCW were 2CP dimers and a dichlorophenol. This observation is consistent with earlier work with the SCWO of phenol, which showed that phenol dimers such as phenoxyphenols and biphenol were major primary products (Thornton and Savage, 1992b).

A simplified global reaction network consistent with the foregoing discussion is displayed in Figure 7. Two parallel primary pathways are shown. One leads to phenol dimers, and the second leads directly to single-ring products such as dichlorophenols and, possibly, ring-opening products. The dimers can undergo secondary oxidation reactions to form ring- 


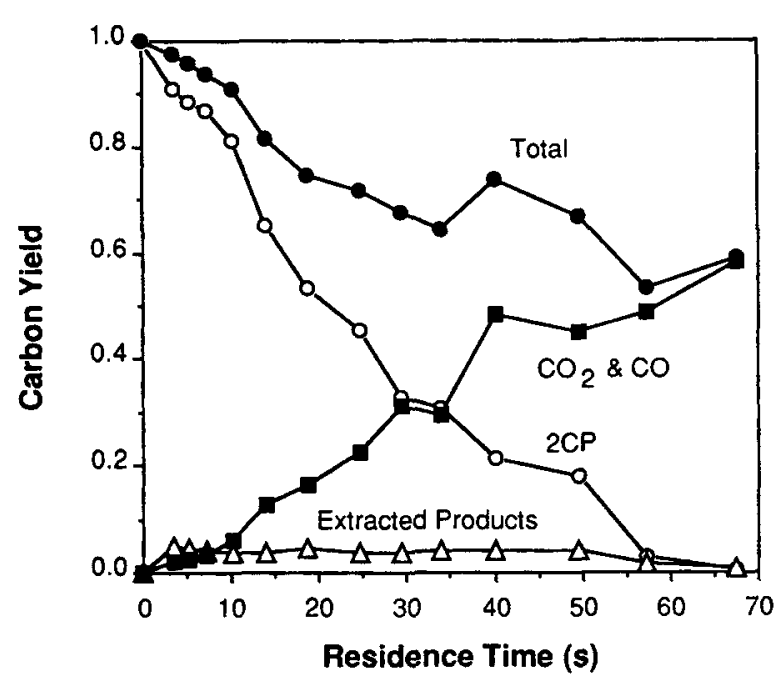

Figure 4. Temporal variations of yields of carbon-containing products (nominal reaction conditions were $380^{\circ} \mathrm{C}, 278 \mathrm{~atm}, 0.0020 \mathrm{M} 2 \mathrm{CP}, 180 \%$ excess oxygen).

opening products and single-ring compounds, which are eventually oxidized to $\mathrm{CO}_{2}$.

\section{Summary and Conclusions}

- The disappearance of 2-chlorophenol during oxidation in near-critical and supercritical water proceeds with a global rate law that is $0.88 \pm 0.06$ order in 2-chlorophenol, $0.41 \pm 0.12$ order in oxygen, and $0.34 \pm 0.17$ order in water. The activation energy is $11.0 \pm 3.8 \mathrm{kcal} / \mathrm{mol}$, and the Arrhenius pre-exponential factor is $10^{2.0 \pm 1.2} \mathrm{M}^{-0.63} \cdot \mathrm{s}^{-1}$. The uncertainties in the parameter estimates represent $95 \%$ confidence intervals.

- The $2 \mathrm{CP}$ oxidation products include $\mathrm{CO}, \mathrm{CO}_{2}, \mathrm{HCl}$, cy-

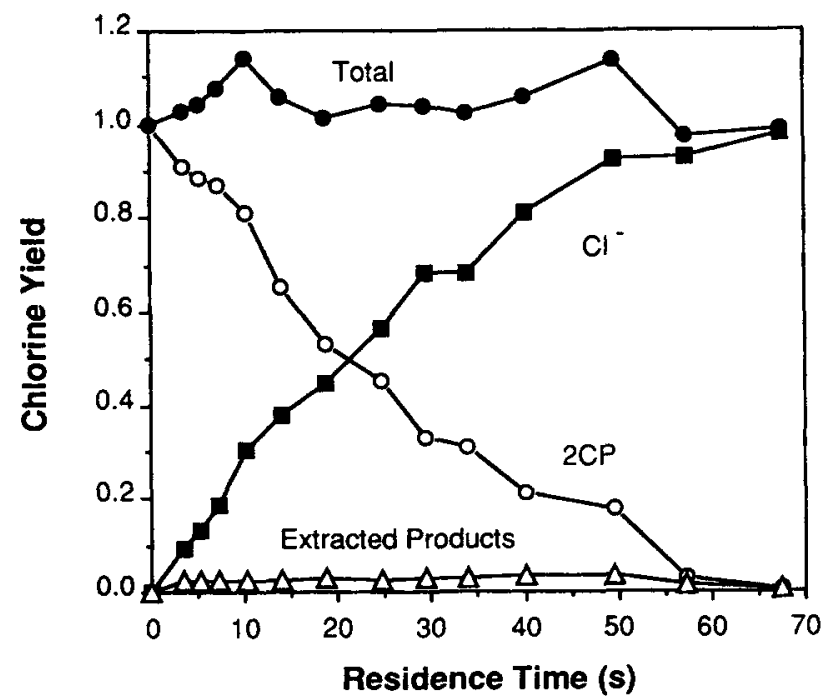

Figure 5. Temporal variations of yields of chlorine-containing products (nominal reaction conditions were $380^{\circ} \mathrm{C}, 278 \mathrm{~atm}, 0.0020 \mathrm{M} 2 \mathrm{CP}, 180 \%$ excess oxygen).

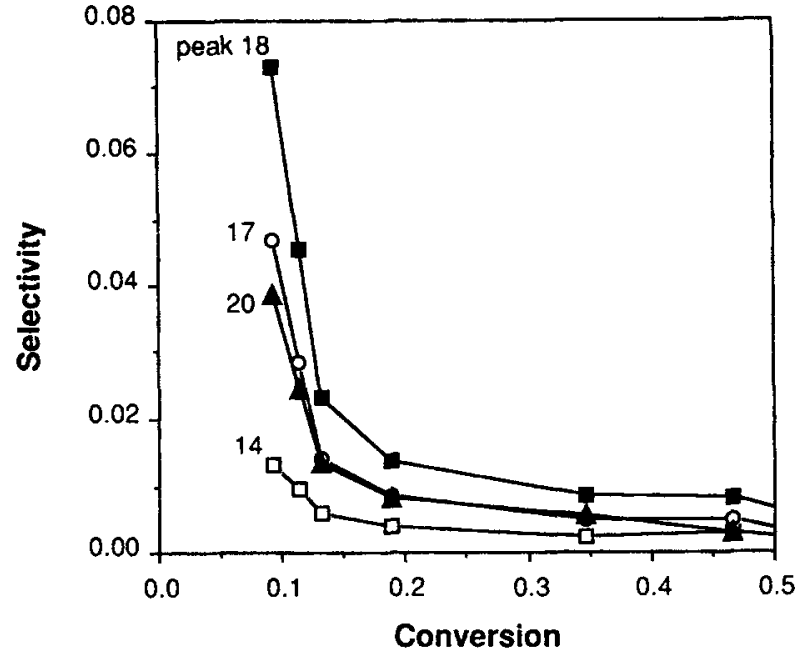

Figure 6. First rank Delplot for dichlorophenoxyphenols (nominal reaction conditions were $380^{\circ} \mathrm{C}, 278$ atm, $0.0020 \mathrm{M} 2 \mathrm{CP}, 180 \%$ excess oxygen).

clodiones, chlorinated phenols, chlorinated hydroxyl $97: z a$ dehydes and hydroxyphenylethanone, chlorinated dibenzodioxins and dibenzofuran, dichlorophenoxyphenols, and dichlorobiphenols.

- The temporal variation of the yields of the carbon containing products was consistent with a global reaction network comprising two parallel primary steps. The first pathway leads to 2CP dimers, and the second pathway leads to single-ring and ring-opening products. The dimers can be converted to ring-opening products, and these are ultimately oxidized to $\mathrm{CO}_{2}$.

- The primary organic products with the highest selectivities were dichlorophenoxyphenols, dichlorobiphenols, and dichlorophenol. Roughly $50 \%$ of the carbon in the $2 \mathrm{CP}$ fed to the reactor was converted to $2 \mathrm{CP}$ dimers at $380^{\circ} \mathrm{C}, 278 \mathrm{~atm}$, $3.6 \mathrm{~s},[2 \mathrm{CP}]_{o}=0.002 \mathrm{M}$, and $180 \%$ excess oxygen. Thus, the primary pathway to $2 \mathrm{CP}$ dimers is clearly important in the overall reaction network.

\section{Acknowledgment}

We acknowledge helpful discussions with Sudhama Gopalan and the financial support of the National Science Foundation (CTS8906859, CTS-8906860 and CTS-9015738).

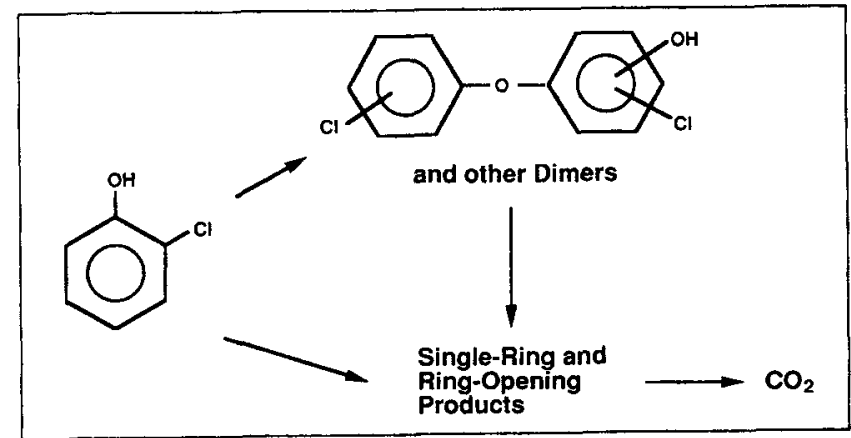

Figure 7. Global reaction network for $2 \mathrm{CP}$ oxidation in SCW. 


\section{Notation}

$A=$ Arrhenius pre-exponential factor

$a=$ reaction order for 2-chlorophenol

$b=$ reaction order for oxygen

$c=$ reaction order for water

$E_{a}=$ activation energy

$M=$ moles per liter

$R=$ gas constant

$T=$ temperature

$\Delta V^{*}=$ activation volume

$X=2$-chlorophenol conversion

\section{Greek letters}

$\tau=$ residence time

\section{Subscripts}

$o=$ inlet

$c=$ critical

\section{Literature Cited}

Baillod, C. R., B. M. Faith, and O. Masi, "Fate of Specific Pollutants During Wet Oxidation and Ozonation," Env. Prog., 1, 217 (1982).

Bhore, N. A., M. T. Klein, and K. B. Bischoff, "The Delplot Technique: a New Method for Reaction Pathway Analysis," Ind. Eng. Chem. Res., 29, 313 (1990).

Dietrich, M. J., T. L. Randall, and P. J. Canney, "Wet Air Oxidation of Hazardous Organics in Wastewater," Env. Prog. , 4, 171 (1985)

Federal Register, "Method 604-Phenols," 49, 43290 (1984).

Fogler, H. S., Elements of Chemical Reaction Engineering, 2nd ed., Prentice-Hall (1992).

Helling, R. K., and J. W. Tester, "Oxidation Kinetics of Carbon Monoxide in Supercritical Water," Energy \& Fuels, 1, 417 (1987).

Helling, R. K., and J. W. Tester, "Oxidation of Simple Compounds and Mixtures in Supercritical Water: Carbon Monoxide, Ammonia, and Ethanol," Environ. Sci. Technol., 22, 1319 (1988).

Levec, J., "Catalytic Oxidation of Toxic Organics in Aqueous Solution," Appl. Catal., 63, L1 (1990).

Li, R., T. D. Thornton, and P. E. Savage, "Kinetics of $\mathrm{CO}_{2}$ Formation from the Oxidation of Phenols in Supercritical Water," Environ. Sci. Technol., in press (1992).
Modell, M., "Supercritical Water Oxidation," in Standard Handbook of Hazardous Waste Treatment and Disposal, H. M. Freeman, ed., Section 8.11, McGraw-Hill, New York (1989).

Silverstein, R. M., G. C. Bassler, and T. C. Morrill, Spectrometric Identification of Organic Compounds, 5th ed., John Wiley \& Sons, New York (1991).

Staszak, C. N., K. C. Malinowski, and W. R. Killilea, "Pilot-Scale Demonstration of MODAR Oxidation Process for the Destruction of Hazardous Organic Waste Materials," Environ. Prog., 6, 39 (1987).

Thornton, T. D., "Phenol Oxidation in Supercritical Water: Reaction Kinetics, Products, and Pathways," PhD Thesis, University of Michigan (1991).

Thornton, T. D., and P. E. Savage, "Phenol Oxidation in Supercritical Water," J. Supercritical Fluids, 3, 240 (1990).

Thornton, T. D., and P. E. Savage, "Kinetics of Phenol Oxidation in Supercritical Water," AIChE J., 38, 321 (1992a).

Thornton, T. D., and P. E. Savage, "Phenol Oxidation Pathways in Supercritical Water," Ind. Eng. Chem. Res., 31, 2451 (1992b).

Thornton, T. D., D. E. LaDue III, and P. E. Savage, "Phenol Oxidation in Supercritical Water: Formation of Dibenzofuran, Dibenzo-p-dioxin, and Related Compounds," Environ. Sci. Technol., 25, 1507 (1991).

Webley, P. A., and J. W. Tester, "Fundamental Kinetics of Methanol Oxidation in Supercritical Water," in Supercritical Fluid Science and Technology, K. P. Johnston and J. M. L. Penninger, eds., ACS Symposium Series No. 406 (1989).

Webley, P. A., and J. W. Tester, "Fundamental Kinetics of Methane Oxidation in Supercritical Water," Energy \& Fuels, 5, 411 (1991).

Webley, P. A., J. W. Tester, and H. R. Holgate, "Oxidation Kinetics of Ammonia and Ammonia-Methanol Mixtures in Supercritical Water in the Temperature Range $530-700^{\circ} \mathrm{C}$ at 246 bar," Ind. Eng. Chem. Res., 30, 1745 (1991).

Wightman, T. J., "Studies in Supercritical Wet Air Oxidation," M.S. Thesis, University of California, Berkeley, CA (1981).

Yang, H. H., "Homogeneous Catalysis in the Oxidation of p-Chlorophenol in Supercritical Water," PhD Thesis, University of Illinois, Urbana-Champaign, IL (1988).

Yang, H. H., and C. A. Eckert, "Homogeneous Catalysis in the Oxidation of p-Chlorophenol in Supercritical Water," Ind. Eng. Chem. Res., 27, 2009 (1988).

Manuscript received Apr. 17, 1992, and revision received July 30, 1992. 